\title{
How to make landscape genetics beneficial for conservation management?
}

\author{
Daniela Keller • Rolf Holderegger • \\ Maarten J. van Strien · Janine Bolliger
}

Received: 7 December 2013/Accepted: 19 November 2014/Published online: 18 December 2014

(C) Springer Science+Business Media Dordrecht 2014

\begin{abstract}
Many landscape genetic studies promise results that can be applied in conservation management. However, only few landscape genetic studies have been used by practitioners. Here, we identified scientific topics in landscape genetics that need to be addressed before results can more successfully be applied in conservation management. For each topic, weaknesses of common practice in landscape genetic analysis are described by presenting examples from current studies and further recommendations for improvements are outlined. First, we suggest matching the extent of the study area with those of conservation management units and the study species' dispersal potential when designing landscape genetic studies. Second, the quality of the underlying statistical models should be optimised, and models should include variables that are useful for management implementation. Third, to further improve the applicability of landscape genetic studies, thresholds for landscape effects on gene flow should be identified. Fourth, landscape genetic models could be used for the development of conservation planning tools, which ideally also incorporate the above described thresholds.
\end{abstract}

D. Keller $\cdot$ R. Holderegger $\cdot$ J. Bolliger

WSL Swiss Federal Research Institute, Zürcherstrasse 111, 8903 Birmensdorf, Switzerland

D. Keller (凶)

FORNAT AG, Universitätstrasse 65, 8006 Zurich, Switzerland e-mail: daniela.keller@fornat.ch

R. Holderegger $\cdot$ J. Bolliger

Department of Environmental Systems Science, ETH Zurich, Universitaetsstrasse 16, CH-8092 Zurich, Switzerland

M. J. van Strien

Planning of Landscape and Urban Systems, ETH Zürich,

Stefano-Franscini-Platz 5, 8093 Zurich, Switzerland
Fifth and as discussed in earlier studies, the use of multiple species and replication at the landscape scale is recommended. Although it appears that only few landscape genetic studies have been applied in practical management until now, examples presented in this article show that landscape genetic methods can provide important information to formulate concrete management implications. Thus, addressing the above-mentioned scientific topics in landscape genetic studies would enhance the benefits of their results for practitioners.

Keywords Landscape variable selection - Statistical model quality - Multi-species studies · Planning tools . Study area extent . Threshold identification

\section{Introduction}

In 2013 it has been 10 years since the publication of the paper that gave rise to the discipline of landscape genetics (Manel et al. 2003; Manel and Holderegger 2013; Bolliger et al. 2014). Landscape genetics combines landscape ecological methods, spatial statistics and population genetic analyses (Holderegger and Wagner 2008). In addition to conservation genetics, landscape genetic analyses provide new possibilities to answer questions which are relevant for conservation management (Segelbacher et al. 2010; Sommer et al. 2013; Bolliger et al. 2014), such as the identification of dispersal barriers or corridors. Consequently, a large number of landscape genetic studies aimed and aims to find answers to species-specific management issues and to provide results that can be used in conservation practice.

The question is whether results from landscape genetic studies are implemented in conservation management and practice? This question is difficult to answer, because, 
contrary to results from scientific studies, reports on planned or implemented conservation measures or conservation policy are rarely published in well-archived literature. Instead, such information is usually documented in "grey literature", like management plans, environmental impact assessments or evaluation reports. As the grey literature on conservation practice is usually difficult to assess, only few studies have searched through it. For instance, Moyle et al. (2003) found that genetic data play a minor role in the formulation of species recovery plans. The minor importance of genetics in conservation practice is also apparent from conservation practitioners' rankings of their most pressing research questions, in which questions related to genetic topics are not or hardly posed (Sutherland et al. 2009; Braunisch et al. 2012). For instance, in another study by Walzer et al. (2013) that identified the 50 most important questions relating to the maintenance and restoration of an ecological continuum in the European Alps, only three questions focussed on gene flow or genetic diversity. It is thus clear that genetics is currently underrepresented in conservation practice (e.g. Howes et al. 2009, Laikre et al. 2009, Koskela et al. 2013, Winter et al. 2013). This also holds true for landscape genetics, where few studies have hitherto been successfully applied in conservation management (Segelbacher et al. 2010). Reasons for this "implementation-gap" are a limited understanding of how genetic methods can be applied in practice, unclear or impractical management implications by geneticists (Moyle et al. 2003), limited communication between practitioners and scientists (Hoban et al. 2013) and high costs of molecular analyses (Howes et al. 2009), despite recently developed new and cheaper molecular technologies (single nucleotide polymorphisms (SNPs) detected by various next generation sequencing methods such as RADseq, Illumina or 454 sequencing; Davey et al. 2011).

An example of a landscape genetic study of which the results have been implemented in policy focussed on the effects of highways on connectivity in desert bighorn sheep Ovis canadensis nelsoni (Epps et al. 2005). This study tested the impact of a single landscape element, namely highways, on gene flow between bighorn sheep populations. The results showed a substantial barrier effect of highways on gene flow among populations of bighorn sheep. The authors thus suggested the establishment of over- or underpasses to enhance gene flow across highways. These suggestions were then considered in the recommendations for actions in the U.S. Fish and Wildlife Service recovery plan published in 2011 (available at http:// www.fws.gov/carlsbad/TEspecies/Recovery/5YearReviews/ 5YearReviewSpeciesList.htm). Among other issues, this recovery plan recommends the construction of wildlife overand underpasses crossing major barriers, the identification of migration routes and the protection of corridors between populations of bighorn sheep. Notably, the above described landscape genetic study published in 2005 is explicitly referenced in the recovery report.

Most landscape genetic studies have only recently been published. It therefore remains to be seen whether their results will more often be implemented in conservation management in the near future. An example is provided by a recent landscape genetic study, which aimed at providing basic information for a recovery plan of the threatened red hills salamander in Alabama (Phaeognathus hubrichti; Apodaca et al. 2012). The authors investigated population genetic structure as well as landscape effects on gene flow of this salamander. Overall, the study found limited contemporary gene flow in a highly fragmented landscape, but higher levels of historical gene flow, which took place before habitat modification. The authors suggested that habitat loss and fragmentation could be potential reasons for this development and recommended to restore the landscape in between occupied patches in addition to the already established protection of the main habitat of the salamander. Such studies, which have been a priori designed with the aim to deliver results of relevance for conservation management, should have high potential for application in future management planning.

Despite the seemingly low impact that landscape genetic studies had in conservation practice so far, the few examples of landscape genetic studies that have successfully been applied by practitioners show that landscape genetics can deliver new insight and could play an important role in conservation management. However, landscape genetic studies that focus on providing useful information for conservation practitioners should, from the beginning, be designed in a way that their results can directly be applied in conservation practice (Hoban et al. 2013). Furthermore, new landscape genetic methods should be developed with a focus on their applicability in conservation (Manel and Holderegger 2013). In this article, we identify several topics of landscape genetic studies on gene flow that need further improvement from the scientific side before results can more widely be used in conservation management. Each topic is briefly introduced and illustrated by examples from previous landscape genetic studies. Subsequently, we present ideas for improvement complimented with recommendations from earlier studies (if available). In particular, we discuss the following topics: (i) the spatial extent of study areas, (ii) the quality of statistical landscape genetic models and selection of landscape predictor (i.e., explanatory or independent) variables, (iii) the quantification of landscape effects and identification of thresholds, (iv) multi-species approaches and replicated landscapes, and (v) the development of planning tools. 


\section{Challenges of landscape genetic methods in view of practical application}

Defining the spatial extent of study areas

An important topic in any landscape genetic study is the definition of the appropriate spatial extent of study areas. Though, matching the spatial extent of study areas with conservation management units (i.e., the area for which a conservation authority is responsible) and species' dispersal potential seem to be two relevant aspects.

In landscape ecology, spatial extent has been defined as the overall area considered in an analysis (Turner 1989). Accordingly, the study area should be designed in a way that it includes a large enough number of populations and landscape elements. Surprisingly, the effect of spatial extent has hardly been analysed in landscape genetics, although it has been shown to have a significant impact (Cushman and Landguth 2010). In a review on spatial and temporal scale in landscape genetics (Anderson et al. 2010), the determination of the spatial extent of the study area was only briefly discussed. These authors suggested choosing a study area that matches the study species' dispersal ability and recommended the creation of an additional buffer zone around this study area.

Another aspect, which has not been discussed so far, but plays an important role for the implementation of landscape genetic results in conservation planning, is the matching of the extent of a study area with the units of conservation management. This aspect can be illustrated with a conservation genetic study on an endangered dragonfly Leucorrhinia caudalis in Switzerland (Keller et al. 2010). When the study was conducted, L. caudalis occurred at nine ponds throughout Switzerland. While seven ponds were close to each other (distance between ponds $\leq 7 \mathrm{~km}$ ) and within the same Cantonal conservation management unit, two ponds were found at distances of 30 and $50 \mathrm{~km}$ apart, each located in a different Canton. A landscape genetic study on the seven closely located ponds aiming at identifying dispersal barriers or corridors could well be used to guide conservation management in order to enhance connectivity between populations of $L$. caudalis. However, the results of a similar study including the two far located populations would be difficult to implement in practice, as such a spatial extent of the study area would very rarely be covered by dispersal across long distances $(\geq 5 \mathrm{~km}$ ) in this dragonfly (Keller et al. 2010). It would also exceed the spatial extent of conservation management units by far. Thus, we recommend setting the spatial extent of a study area so that it covers the maximum dispersal distance of the study species several times and that it also corresponds to conservation management units. If the study area is either too large or too small, practitioners will be unable to implement recommendations, or will regard the results as irrelevant for management, respectively. On the other hand, genetic data could of course be used to delineate conservation management units and inform conservation management on adequate extent (e.g. Funk et al. 2012). Whereas conservation management units may traditionally have been defined by administrative or geographical boundaries, landscape genetic analyses could help in forming conservation management units around groups of well-connected populations.

Improving statistical models in landscape genetics: quality and selected landscape variables

Another reason why landscape genetic studies might rarely lead to implementation in conservation plans is the underlying statistical models. Both the quality of the models (here discussed by means of model fits) as well as the landscape predictor variables included in the models can make the reliability and relevance of landscape genetic results questionable.

First, if statistical models in landscape genetic analyses show a low model fit, it is problematic to base recommendations for conservation planning on their uncertain outcome. For example, very low but significant model fits were found in a landscape genetic study on two common and widespread grasshopper species Chorthippus albomarginatus and Chorthippus biguttulus $\left(\mathrm{R}^{2} \leq 0.1\right.$ in all models; Keller et al. 2013b). Only model fits of statistical models for a third more specialised species Gomphocerippus rufus were somewhat higher $\left(\mathrm{R}^{2}=0.25\right.$ for the best model). Although these models were significant because of a large enough number of observations (i.e., $\geq 30$ sampled populations), it is questionable to draw conclusions from models explaining less than $25 \%$ of the variance in gene flow among populations. Similarly low values were detected in a landscape strip analysis on a bush cricket Metrioptera roeselii (Holzhauer et al. 2006), where the authors found significant $R^{2}$ values of $0.11-0.18$. Even lower significant $R^{2}$ values $\left(R^{2} \leq 0.005\right)$ were detected in a least-cost path analysis on American marten (Martes americana; Broquet et al. 2006). In general, ecological studies often find little variance explained. This has been shown in a meta-analysis by Moller and Jennions (2002), which found that the main predictive factor in ecological models often explains less than $10 \%$ of the variance (in about $80 \%$ of examples). However, other landscape genetic studies found well supported models. Three examples of such studies are Spear et al. (2005), who detected high $R^{2}$ values $\left(R^{2}=0.83\right)$ in a landscape genetic study on the salamander Ambystoma tigrinum melanostictum, Van Strien et al. (2012), who detected a similarly high 
$\mathrm{R}_{\beta}^{2}$ value $\left(\mathrm{R}_{\beta}^{2}=0.81\right)$ in a statistical landscape genetic model on the damselfly Coenagrion mercuriale, and Weckworth et al. (2013), who detected high Mantel $r$ values (Mantel $r=0.9$ ) in a study on woodland caribou (Rangifer tarandus). However, note that smaller sample sizes (i.e., 10,13 and 8 populations in the latter three studies compared to $\geq 30$ populations in the grasshopper studies mentioned above) often lead to higher model fits if $R^{2}$ values are not adjusted for sample size (Montgomery and Morrison 1973). Also note that the use of $\mathrm{R}^{2}$ and AIC measures in the statistical analysis of landscape genetic data is under debate (Goldberg and Waits 2010; Van Strien et al. 2012).

Second, landscape elements included as predictor variables in landscape genetic statistical models should be chosen carefully considering their importance and management potential in conservation practice. The same accounts for landscape elements used to create resistance surfaces to calculate least-cost paths (Adriaensen et al. 2003) or resistance distances (McRae and Beier 2007). Many landscape genetic studies on amphibians, for example, tested the effects of the landscape elements roads, rivers and mountain ridges on gene flow (Emel and Storfer 2012). While results showing a barrier effect of roads on gene flow (e.g. Arens et al. 2007; Van Buskirk 2012; Sawaya et al. 2014) could lead to the implementation of road underpasses or tunnels, a negative effect of a mountain ridge is mainly of ecological or scientific relevance and could be used to define conservation management units (see above), but there is nothing that conservation management could do about it. Nevertheless, basic knowledge about species-specific dispersal characteristics can guide planning in conservation management, and knowledge on general species ecology is high on the priority list of conservation practitioners (Braunisch et al. 2012).

Another challenge is that the landscape elements considered in landscape genetic studies are often too generally defined from a thematic or spatial point of view. For instance, the shape and explicit location of a landscape element along a dispersal path or within a dispersal corridor has hardly been considered in landscape genetic analyses. In fact, many studies simply assessed the area, length or presence (binary data, 0/1) of a landscape element in a dispersal corridor or transect (e.g. Emaresi et al. 2011; Keller et al. 2012). However, both the shape and location of a landscape element can influence its significance in a landscape genetic study. This is illustrated in Fig. 1 by means of the landscape elements roads, forests and habitat, assuming that both roads and forests act as barriers to gene flow and habitat acts as a facilitator. It becomes clear that the effect of a landscape element on gene flow varies with different shape and/or location, while its area, length or proportion remains the same (Fig. 1). This was, for instance, shown by a landscape
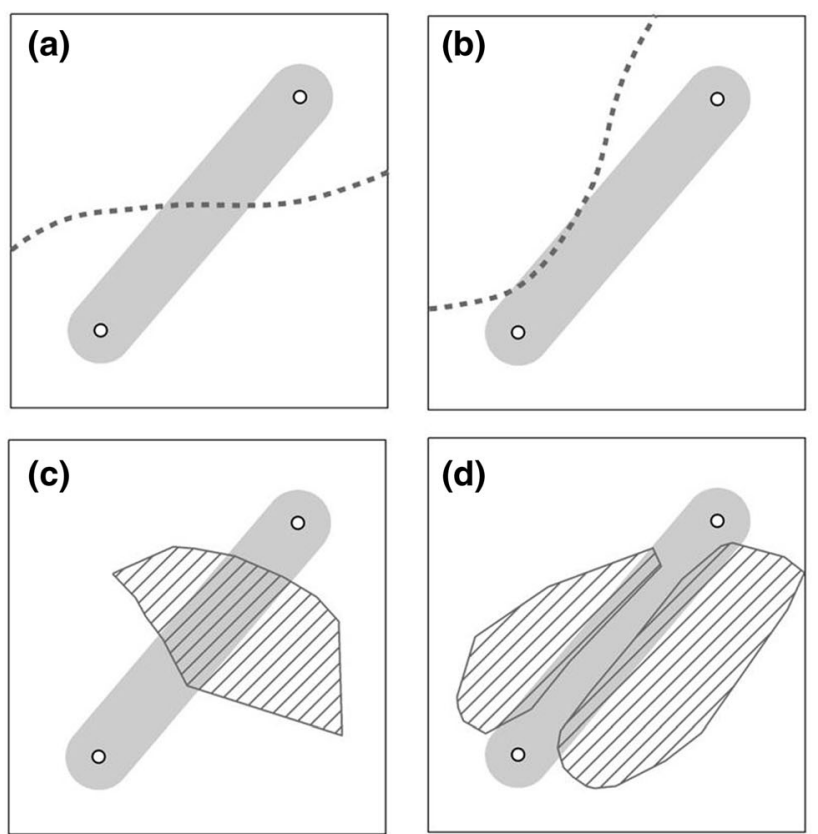

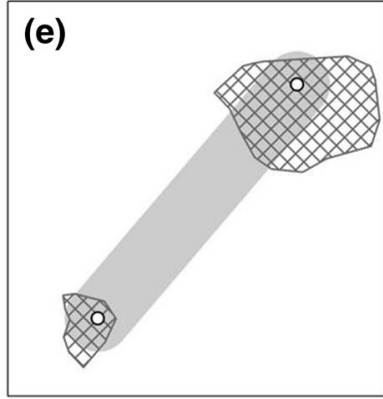

- Population

$-=-$ Road

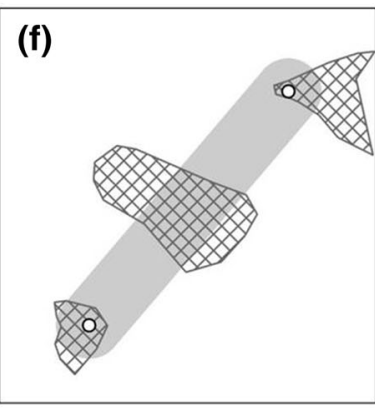

Forest (barrier)

Habitat
Fig. 1 Effect of shape and explicit location of landscape elements in landscape genetic studies. a-f show different shapes and positions of three landscape elements within a straight-line transect (shown in grey) between two populations (circles). a, b show different locations of a linear landscape barrier (e.g. a road; dashed line), which has the same length within both corridors in (a) and (b). c, d illustrate differently shaped patchy landscape barriers (e.g. a forest; hatched areas), which have the same area within the corridor. The last example depicts a species' habitat (cross-hatched area). While the proportion and area of habitat is equal in both corridors $(\mathbf{e}, \mathbf{f})$, example (f) shows a patch of habitat between the two populations, which might act as a stepping stone during movement

genetic study on the bush-cricket $M$. roeselii, which detected a negative effect on gene flow by roads intersecting with dispersal paths, in contrast to parallel roads, which had none or even a positive effect (i.e., road verges acting as dispersal corridors; Holzhauer et al. 2006). Furthermore, the negative effect of particular types of roads on dispersal and gene flow could be diluted or absent if all types of roads were summarised into a single landscape category. As, for instance, 
shown by Holderegger and Di Giulio (2010), the effect of narrow and infrequently used roads can differ substantially from that of wide and busy roads or highways. Similarly, a simulation study, which tested for the effects of several thematic resolutions on the correlation between genetic distance and least-cost path distance, found that results were sensitive to thematic resolution (Cushman and Landguth 2010). Obviously, for the selection of landscape elements one cannot give general recommendations as this selection will have to be adapted to particular research questions, not to say practical questions, and study species with their individual dispersal characteristics. Landscape elements relevant to the habitat preferences of the focal species can perhaps be derived from resource selection functions, which are usually calibrated with radio telemetry data and have recently been used in several landscape genetic studies to parameterise resistance surfaces (Shafer et al. 2012; Weckworth et al. 2013). Furthermore, for some species it is important to consider temporal variation in habitat use (Yannic et al. 2014). Selecting and defining landscape variables for landscape genetics remains especially challenging for little studied and cryptic species as for instance many insect species. Therefore, we recommend to experiment with several spatial and thematic resolutions, especially including those landscape variables with management implications, when performing landscape genetic research.

Quantification of landscape effects and identification of thresholds

By quantifying landscape effects on gene flow and identifying thresholds in landscape genetic studies, implementations for practical management could directly be derived.

Many landscape genetic studies aim to identify landscape elements acting as possible barriers or facilitators of dispersal (e.g. Segelbacher et al. 2010; Storfer et al. 2010; Keller et al. 2012). Although the studied landscape elements often show a significant negative or positive correlation with gene flow, it remains unclear whether one landscape element has a higher impact on gene flow than others or how strongly gene flow is reduced or facilitated by a particular element. A recent landscape genetic study (Van Buskirk 2012) aimed at quantifying the effects of several landscape elements on gene flow between frog (Rana temporaria) and newt (Triturus alpestris) populations, using a transect analysis with lens-shaped transects. The study found, for instance, that the presence of secondary roads reduced gene flow (measured as $\mathrm{N}_{\mathrm{e}} \mathrm{m}$ ) in $T$. alpestris by $4.9 \%$, highways lowered $\mathrm{N}_{\mathrm{e}} \mathrm{m}$ by $40 \%$ and urban areas decreased gene flow by $42 \%$. This example shows that results from transect analyses are able, in contrast to least-cost path analyses, to estimate the direct effects of several landscape elements on gene flow and demonstrates a possibility to quantify these effects. Such results could, for instance, help practitioners to prioritise when planning management measures to mitigate landscape barrier effects.

Furthermore, the identification of thresholds of landscape effects on gene flow might potentially result in concrete guidelines for decisions in conservation management (Méndez et al. 2014). For instance, open land may be identified as a barrier to gene flow in a landscape genetic study on a forest-dwelling animal. However, practitioners may like to know how much intervening open land among forests would become problematic for gene flow of a study species. Such information could be used to identify locations where management should primarily be applied. Despite the high application potential, landscape genetic studies have only recently begun to identify such thresholds. There are several ways in which threshold effects of landscape elements on gene flow could be determined in landscape genetic studies.

First, thresholds could be identified with landscape corridor analysis (i.e., transect or strip analysis; Pavlacky et al. 2009; Angelone et al. 2011; Emaresi et al. 2011; Keller et al. 2012; Van Buskirk 2012), in which the proportion (or the length, area, density) of a landscape element within a corridor is correlated with a measure of gene flow between all pairs of populations. Figure 2 illustrates this idea based on a dataset of the wetland grasshopper Stethophyma grossum studied in the Oberaargau region in

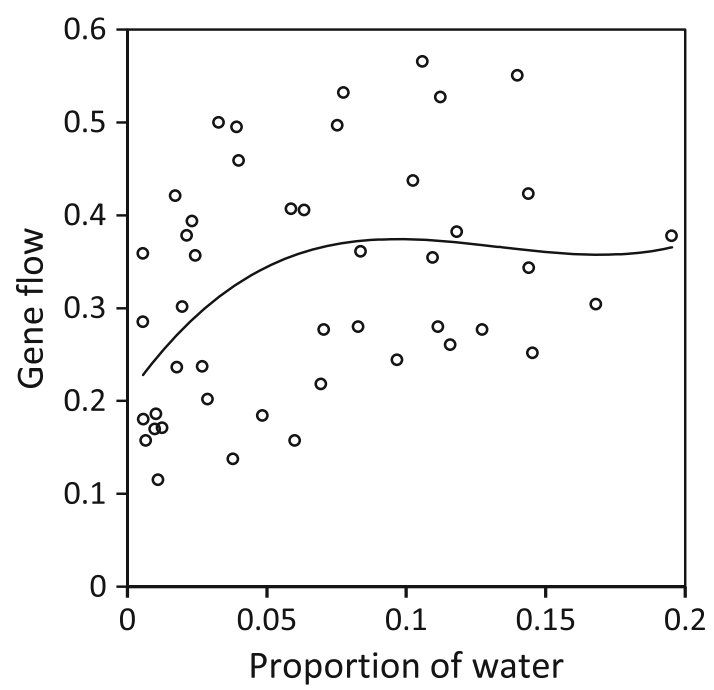

Fig. 2 Detection of a threshold by correlating the proportion of a landscape element with a measure of gene flow. Shown is the correlation between the proportion of water bodies and gene flow (i.e., mean assignment probabilities) between populations of the wetland grasshopper S. grossum studied in Switzerland (Keller et al. 2013a, b). Only neighbouring population pairs less than $3 \mathrm{~km}$ apart from each other were considered. Beyond the threshold (i.e., 0.07), an increase of the proportion of water does not result in an increase in gene flow 
Switzerland (Keller et al. 2013a). It shows the correlation between the landscape element water bodies, which has earlier been identified as a facilitator to gene flow in $S$. grossum (Keller et al. 2013a), and a measure of gene flow (i.e., pairwise mean assignment probability). For all pairs of nearest neighbouring populations (i.e., Gabriel graph populations), the proportion of water bodies within a straight-line corridor (corridor width $=100 \mathrm{~m}$ ) was then correlated to gene flow. In this example, an increase in gene flow with increasing proportion of water bodies can only be observed up to a threshold of roughly $7 \%$ water bodies within the dispersal corridor. Based on this knowledge, managers could easily identify populations of $S$. grossum, which are well connected and populations between which the creation of new water bodies would facilitate gene flow. Such an approach could also be taken for landscape elements showing a barrier effect on gene flow, as for instance forests did in S. grossum. The approach described above is especially useful for landscape elements that strongly affect dispersal and gene flow. It also nicely illustrates the high potential that graph theory and network analysis can potentially have in defining thresholds (Albert et al. 2013).

Second, instead of considering linear relationships, as with Mantel tests, partial Mantel tests and multiple linear regression on distance matrices, which are the most often used statistical methods in current landscape genetic studies (Storfer et al. 2010), the detection of thresholds could be facilitated by applying non-parametric regression techniques (Austin 2002). This could lead to ecologically more realistic response curves (as suggested in Fig. 2) and to higher model fits.

Third, thresholds could also be identified when using multiple or replicated landscapes (see below). This is nicely illustrated by a study of Balkenhol et al. (2013) on a small mammal (Marmosops incanus) inhabiting forest fragments of the Brazilian Atlantic forest. These authors studied gene flow in four study regions of similar size but dramatically different levels of forest fragmentation, ranging from $86 \%$ to only $11 \%$ forest cover. While the species was no longer present in the landscape with $11 \%$ forest cover, the results suggested the existence of a threshold effect of forest fragmentation on gene flow in the other study areas: in the $31 \%$ forest cover landscape genetic differentiation was significantly increased, while the 49 and $86 \%$ forest cover landscapes showed similar genetic differentiation among populations. This example also exemplifies that genetic consequences of fragmentation might become obvious before any effects of fragmentation on species occurrence become detectable.

Thresholds may not only be suitable to aid practitioners in conservation planning (e.g. when does a barrier become problematic?), but will also be helpful as an evaluation tool for implemented conservation measures. For instance, for the evaluation of newly established highway under- or overpasses, managers may want to know how much increase in gene flow should be expected after a certain time before the construction can be deemed successful (Corlatti et al. 2009). Although these thresholds will be difficult to establish from empirical genetic data, simulation studies may help in establishing such thresholds.

A promising approach to select locations of special importance for management action can be achieved by weighting corridors as shown by Epps et al. (2007) or Parks et al. (2013). In a landscape genetic study on wolverines (Gulo gulo) in the Rocky Mountains, Parks et al. (2013) first identified wildlife corridors using least-cost corridor methods and then weighted corridors according to levels of gene flow. With the resulting connectivity maps, key areas of connectivity, whose maintenance is of high importance for conservation management, were identified.

\section{Choosing study species and study landscapes}

The use of multi-species studies as well as replication at the landscape scale are two important topics in landscape genetic studies.

As criticised in a review on the application of landscape genetic methods in conservation practice (Segelbacher et al. 2010), most landscape genetic studies are conducted on single species in a single specific landscape. Thus, the results of most landscape genetic studies can hardly be generalised or applied to other species or areas and can, strictly spoken, only be used for the conservation management of that particular species in that particular landscape. This, of course, strongly limits their relevance for conservation management.

In fact, few landscape genetic studies have used a multispecies approach, and these studies showed very diverse outcomes. Richardson (2012), for instance, found different landscape effects on population connectivity for a salamander and a frog species even though these two species had many ecological traits in common and were studied in the same landscape. Such species-specific results were also detected in other multi-species landscape genetic studies (e.g. Manier and Arnold 2006; Steele et al. 2009; Frantz et al. 2012; Poelchau and Hamrick 2012; Sawaya et al. 2014). In contrast, some studies identified convergent landscape effects in different species (e.g. Goldberg and Waits 2010), and Delaney et al. (2010) even found similar reductions in gene flow in response to urban areas in three lizard and one bird species. These examples emphasise the importance of analysing multiple species when developing guidelines for conservation management. For instance, the overlay (Storfer et al. 2010) of dispersal routes (e.g. leastcost paths or least-cost corridors) of several species in a 
study landscape should indicate those areas that are highly used and whose protection would be beneficial for many species. Figure 3 illustrates such an overlay of most likely dispersal paths of three insect species in a fragmented agricultural landscape in the Oberaargau region in Switzerland (Van Strien et al. 2012; Keller et al. 2013a, b). In this study, most likely dispersal paths were calculated with least-cost transect analysis (Van Strien et al. 2012).

Although Holderegger and Wagner (2008) had already pointed to the importance of replicating study areas in landscape genetic studies, only a few recent studies have considered several study areas in landscape genetic analysis (e.g. Moore et al. 2011; Short Bull et al. 2011; Munshi-South 2012; Rasic and Keyghobadi 2012; Balkenhol et al. 2013; Trumbo et al. 2013). Although conservation practitioners may be more interested in local or regional studies that focus on ecological processes specific to their management area, information from replicated studies provides general management guidelines, which are applicable to other landscapes as well. Short Bull et al. (2011) demonstrated in a large, replicated study (i.e., 12 study areas) on black bears that the effect of various landscape elements on gene flow fluctuates between study areas. These authors suggested that only highly variable landscape elements will significantly influence gene flow in landscape genetic models. Accordingly, in studies without landscape replication, a non-significant effect of certain landscape elements on gene flow must be interpreted with care. However, landscape elements showing significant effects on gene flow

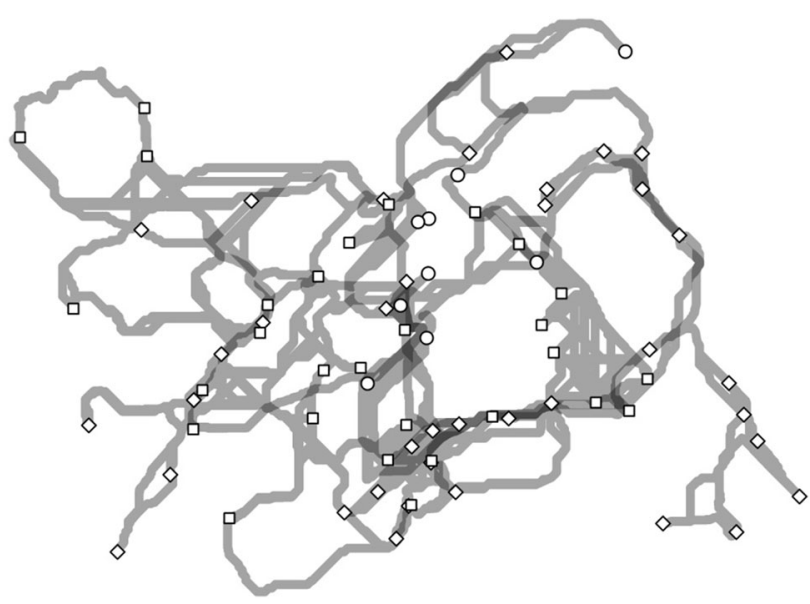

Fig. 3 Identification of highly used dispersal routes by an overlay of most likely dispersal paths of three insect species (damselfly $C$. mercuriale, circles; grasshopper S. grossum, diamonds; grasshopper G. rufus, squares) sampled in a study region in Switzerland. Paths were calculated with least-cost transect analysis (Van Strien et al. 2012). Dark-grey sections show overlapping dispersal paths, potentially used by all three species. They are thus of high importance in insect conservation management in several study areas can safely be inferred (and communicated) as barriers or facilitators to gene flow. These are also the landscape elements that practitioners are most interested in as they are of general importance. However, if landscape elements consistently show divergent impacts on gene flow in different landscapes, area-specific conservation management has to be considered (Trumbo et al. 2013).

In summary, both the consideration of several species and the replication of study landscapes in landscape genetic analyses would provide most useful information for conservation practice, as it allows for generalisation of landscape genetic results to other areas and (potentially) species.

Use of statistical landscape genetic models as planning tools

The application of predictive landscape genetic models would provide additional possibilities for conservation planning. Once statistical landscape genetic models reach a satisfying quality, they can be used to predict the influence of landscape change on gene flow. For instance, a practitioner may want to know what and how large the effect will be on the existing network of populations connected by gene flow if a new stepping stone habitat is established at a certain location or whether the building of a residential area has a negative effect on gene flow at the landscape scale. The potential of such predictions has already been recognised in earlier reviews on landscape genetics (Storfer et al. 2007; Spear et al. 2010). Spear et al. (2010) stated that predictive studies would be highly relevant for conservation management but difficult to perform. So far, very few landscape genetic studies have experimented with predictive landscape genetic models. Van Strien et al. (2013) presented an approach to predict the impact of landscape change on gene flow between populations of a grasshopper species. Possible landscape change was represented in several scenarios, which simulated restoration, rezoning, construction and the establishment of a new population. While for some scenarios, models predicted a significant change in gene flow, other scenarios had no significant effect on gene flow. Another potential application of predictive landscape genetic studies is in predicting the effects of climate change on genetic patterns. Wasserman et al. (2013) used landscape resistance scenarios calibrated with current and future climatic conditions to determine the expected changes in habitat availability and fragmentation and the resulting changes in genetic diversity and gene flow for the American marten ( $M$. americana). Apart from a decrease in habitat availability and an increase in fragmentation, the authors found that gene flow and overall genetic 
Steps in a

landscape

genetic study
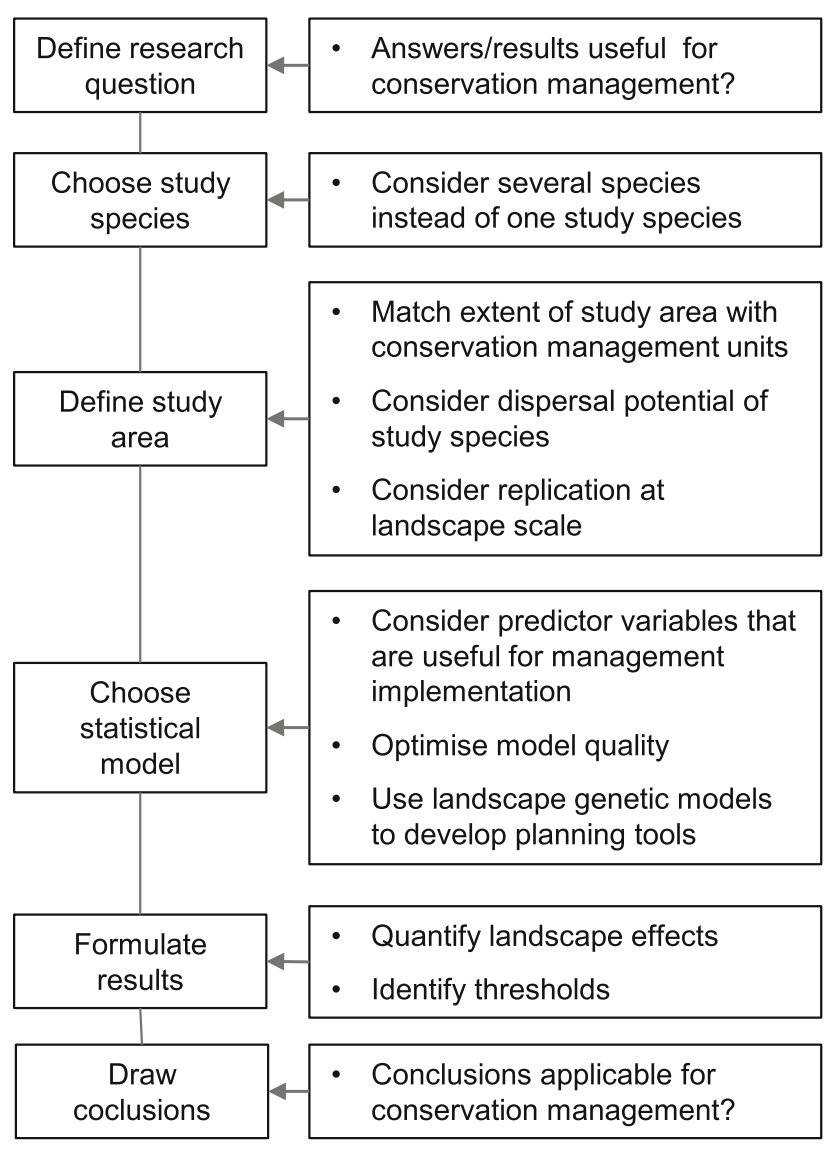

Fig. 4 Flowchart of aspects that should be taken into consideration when planning a landscape genetic study in order to make it beneficial for implementation in conservation management

diversity are expected to decrease under future climate. The authors also pinpointed locations that could potentially become landscape barriers under future climate; information that is particularly helpful for conservation practitioners to prioritise conservation efforts. These studies demonstrate how predictive models can be applied in conservation management. However, to be fully implemented in conservation management these approaches need further methodological development. For instance, the method presented by Van Strien et al. (2013) could be improved by using non-linear dispersal transects or multiple dispersal routes and by using different study landscapes for cross-validation (instead of sub-sampling within the same landscape). Moreover, including the thresholds of landscape elements on gene flow discussed above in predictive models, would provide a very helpful tool for management planning. This has, however, never been achieved so far.

\section{Conclusions}

As landscape genetic analyses have high application potential in conservation management, it is desirable that scientists plan landscape genetic studies in a way that their results can be better applied in practice (Fig. 4). To achieve this goal, good communication between scientists and practitioners is essential (Moyle et al. 2003; Howes et al. 2009). However, good communication is only successful if scientific results of landscape genetic studies are relevant from a practitioner's point of view. They must also be reliable and accurate from a scientific point of view. So far, few landscape genetic studies were successfully implemented in conservation management. Above, we discussed several scientific topics whose improvement and further development would enhance the application of landscape genetic studies in conservation. In summary, we suggested that (i) the spatial extent of a landscape genetic study should correspond to conservation management units and species-specific dispersal characteristics; (ii) landscape genetic models should be optimised to deliver better-supported results, and landscape parameters should be chosen by considering their use in practical application; (iii) the identification of thresholds and the quantification of landscape effects on gene flow, e.g. in form of thresholds as well as (iv) the development of planning tools ideally including such thresholds would enable the formulation of concrete management recommendations; (v) the consideration of multi-species studies and replication at the landscape scale would allow drawing general conclusions, which are of high priority in conservation management. In our opinion, many questions of relevance to practice can already be answered by using existing methods of conservation genetics. However, by improving the above mentioned aspects, the particular benefits of landscape genetic studies, i.e., including the landscape aspect when analysing population connectivity, would become increasingly useful for practitioners.

Acknowledgments We thank the GENEREACH Project funded by the Competence Center Environment and Sustainability of the ETH Domain for financial support and two anonymous referees for comments on the manuscript.

\section{References}

Adriaensen F, Chardon JP, De Blust G, Swinnen E, Villalba S, Gulinck H, Matthysen E (2003) The application of "least-cost" modelling as a functional landscape model. Landsc Urban Plan 64:233-247

Albert EM, Fortuna MA, Godoy JA, Bascompte J (2013) Assessing the robustness of networks of spatial genetic variation. Ecol Lett 16:86-93 
Anderson CD, Epperson BK, Fortin MJ, Holderegger R, James PMA, Rosenberg MS, Scribner KT, Spear S (2010) Considering spatial and temporal scale in landscape-genetic studies of gene flow. Mol Ecol 19:3565-3575

Angelone S, Kienast F, Holderegger R (2011) Where movement happens: scale-dependent landscape effects on genetic differentiation in European tree frog. Ecography 34:714-722

Apodaca JJ, Rissler LJ, Godwin JC (2012) Population structure and gene flow in a heavily disturbed habitat: implications for the management of the imperilled Red Hills salamander (Phaeognathus hubrichti). Conserv Genet 13:913-923

Arens P, van der Sluis T, van't Westende WPC, Vosman B, Vos CC, Smulders MJM (2007) Genetic population differentiation and connectivity among fragmented Moor frog (Rana arvalis) populations in The Netherlands. Landsc Ecol 22:1489-1500

Austin MP (2002) Spatial prediction of species distribution: an interface between ecological theory and statistical modelling. Ecol Model 157:101-118

Balkenhol N, Pardini R, Cornelius C, Fernandes F, Sommer S (2013) Landscape-level comparison of genetic diversity and differentiation in a small mammal inhabiting different fragmented landscapes of the Brazilian Atlantic forest. Conserv Genet 14:355-367

Bolliger J, Lander T, Balkenhol N (2014) Landscape genetics since 2003: status, challenges and future directions. Landsc Ecol 29:361-366

Braunisch V, Home R, Pellet J, Arlettaz R (2012) Conservation science relevant to action: a research agenda identified and prioritized by practitioners. Biol Conserv 153:201-210

Broquet T, Ray N, Petit E, Fryxell JM, Burel F (2006) Genetic isolation by distance and landscape connectivity in the American marten (Martes americana). Landsc Ecol 21:877-889

Corlatti L, Hackländer K, Frey-Roos F (2009) Ability of wildlife overpasses to provide connectivity and prevent genetic isolation. Conserv Biol 23:548-556

Cushman SA, Landguth EL (2010) Scale dependent inference in landscape genetics. Landsc Ecol 25:967-979

Davey JW, Hohenlohe PA, Etter PD, Boone JQ, Catchen JM, Blaxter ML (2011) Genome-wide genetic marker discovery and genotyping using next-generation sequencing. Nat Rev Genet 12:499-510

Delaney KS, Riley SPD, Fisher RN (2010) A rapid, strong, and convergent genetic response to urban habitat fragmentation in four divergent and widespread vertebrates. PLoS ONE 5:11

Emaresi G, Pellet J, Dubey S, Hirzel AH, Fumagalli L (2011) Landscape genetics of the Alpine newt (Mesotriton alpestris) inferred from a strip-based approach. Conserv Genet 12:41-50

Emel SL, Storfer A (2012) A decade of amphibian population genetic studies: synthesis and recommendations. Conserv Genet 13:1685-1689

Epps CW, Palsboll PJ, Wehausen JD, Roderick GK, Ramey RR, McCullough DR (2005) Highways block gene flow and cause a rapid decline in genetic diversity of desert bighorn sheep. Ecol Lett 8:1029-1038

Epps CW, Wehausen JD, Bleich VC, Torres SG, Brashares JS (2007) Optimizing dispersal and corridor models using landscape genetics. J Appl Ecol 44:714-724

Frantz AC, Bertouille S, Eloy MC, Licoppe A, Chaumont F, Flamand MC (2012) Comparative landscape genetic analyses show a Belgian motorway to be a gene flow barrier for red deer (Cervus elaphus), but not wild boars (Sus scrofa). Mol Ecol 21:3445-3457

Funk WC, McKay JK, Hohenlohe PA, Allendorf FW (2012) Harnessing genomics for delineating conservation units. Trends Ecol Evol 27:489-496

Goldberg CS, Waits LP (2010) Comparative landscape genetics of two pond-breeding amphibian species in a highly modified agricultural landscape. Mol Ecol 19:3650-3663
Hoban SM, Hauffe HC, Pérez-Espona S, Arntzen JW, Bertorelle G, Bryja J, Frith K, Gaggiotti OE, Galbusera P, Godoy JA, Hoelzel AR, Nichols RA, Primmer CR, Russo I-R, Segelbacher G, Siegismund HR, Sihvonen M, Vernesi C, Vilà C, Bruford MW (2013) Bringing genetic diversity to the forefront of conservation policy and management. Conserv Genet Res 5:593-598

Holderegger R, Di Giulio M (2010) The genetic effects of roads: a review of empirical evidence. Basic Appl Ecol 11:522-531

Holderegger R, Wagner HH (2008) Landscape genetics. Bioscience 58:199-207

Holzhauer SIJ, Ekschmitt K, Sander AC, Dauber J, Wolters V (2006) Effect of historic landscape change on the genetic structure of the bush-cricket Metrioptera roeseli. Landsc Ecol 21:891-899

Howes BJ, Pither R, Prior KA (2009) Conservation implications should guide the application of conservation genetics research. Endanger Species Res 8:193-199

Keller D, Brodbeck S, Floss I, Vonwil G, Holderegger R (2010) Ecological and genetic measurements of dispersal in a threatened dragonfly. Biol Conserv 143:2658-2663

Keller D, Van Strien MJ, Holderegger R (2012) Do landscape barriers affect functional connectivity of populations of an endangered damselfly? Freshw Biol 57:1373-1384

Keller D, Holderegger R, Van Strien MJ (2013a) Spatial scale affects landscape genetic analysis of a wetland grasshopper. Mol Ecol 22:2467-2482

Keller D, Van Strien MJ, Herrmann M, Bolliger J, Edwards PJ, Ghazoul J, Holderegger R (2013b) Is functional connectivity in common grasshopper species affected by fragmentation in an agricultural landscape? Agric Ecosyst Environ 175:39-46

Koskela J, Lefèvre F, Schueler S, Kraigher H, Olrik DC, Hubert J, Longauer R, Bozzano M, Yrjänä L, Alizoti P, Rotach P, Vietto L, Bordács S, Myking T, Eysteinsson T, Souvannavong O, Fady B, De Cuyper B, Heinze B, von Wühlisch G, Ducousso A, Ditlevsen B (2013) Translating conservation genetics into management: Pan-European minimum requirements for dynamic conservation units of forest tree genetic diversity. Biol Conserv 157:39-49

Laikre L, Allendorf WF, Aroner LC, Baker CS, Gregovich DP, Hansen MM, Jackson JA, Kendall KC, McKelvey K, Neel MC, Olivieri I, Ryman N, Schwartz MK, Bull RS, Stetz JB, Tallmon DA, Taylor BL, Vojta CD, Waller DM, Waples RS (2009) Neglect of genetic diversity in implementation of the convention on biological diversity. Conserv Biol 24:86-88

Manel S, Holderegger R (2013) Ten years of landscape genetics. Trends Ecol Evol 28:614-621

Manel S, Schwartz MK, Luikart G, Taberlet P (2003) Landscape genetics: combining landscape ecology and population genetics. Trends Ecol Evol 18:189-197

Manier MK, Arnold SJ (2006) Ecological correlates of population genetic structure: a comparative approach using a vertebrate metacommunity. Proc R Soc B Biol Sci 273:3001-3009

McRae BH, Beier P (2007) Circuit theory predicts gene flow in plant and animal populations. Proc Natl Acad Sci USA 104:19885-19890

Méndez M, Vögeli M, Tella JL, Godoy JA (2014) Joint effects of population size and isolation on genetic erosion in fragmented populations: finding fragmentation thresholds for management. Evol Appl 7:506-518

Moller AP, Jennions MD (2002) How much variance can be explained by ecologists and evolutionary biologists? Oecologia 132:492-500

Montgomery DB, Morrison DG (1973) A note on adjusting $\mathrm{R}^{2}$. J Financ 28:1009-1013

Moore JA, Tallmon DA, Nielsen J, Pyare S (2011) Effects of the landscape on boreal toad gene flow: does the pattern-process relationship hold true across distinct landscapes at the northern range margin? Mol Ecol 20:4858-4869 
Moyle LC, Stinchcombe JR, Hudgens BR, Morris WF (2003) Conservation genetics in the recovery of endangered animal species: a review of US endangered species recovery plans (1977-1998). Anim Biodivers Conserv 26:85-95

Munshi-South J (2012) Urban landscape genetics: canopy cover predicts gene flow between white-footed mouse (Peromyscus leucopus) populations in New York city. Mol Ecol 21: 1360-1378

Parks SA, McKelvey KS, Schwartz MK (2013) Effects of weighting schemes on the identification of wildlife corridors generated with least-cost methods. Conserv Biol 27:145-154

Pavlacky DC, Goldizen AW, Prentis PJ, Nicholls JA, Lowe AJ (2009) A landscape genetics approach for quantifying the relative influence of historic and contemporary habitat heterogeneity on the genetic connectivity of a rainforest bird. Mol Ecol 18:2945-2960

Poelchau MF, Hamrick JL (2012) Differential effects of landscapelevel environmental features on genetic structure in three codistributed tree species in Central America. Mol Ecol 21:4970-4982

Rasic G, Keyghobadi N (2012) From broadscale patterns to fine-scale processes: habitat structure influences genetic differentiation in the pitcher plant midge across multiple spatial scales. Mol Ecol 21:223-236

Richardson JL (2012) Divergent landscape effects on population connectivity in two co-occurring amphibian species. Mol Ecol 21:4437-4451

Sawaya MA, Kalinowski ST, Clevenger AP (2014) Genetic connectivity for two bear species at wildlife crossing structures in Banff National Park. Proc R Soc B Biol Sci 28:20131705

Segelbacher G, Cushman SA, Epperson BK, Fortin MJ, Francois O, Hardy OJ, Holderegger R, Taberlet P, Waits LP, Manel S (2010) Applications of landscape genetics in conservation biology: concepts and challenges. Conserv Genet 11:375-385

Shafer ABA, Northrup JM, White KS, Boyce MS, Côté SD, Coltman DW (2012) Habitat selection predicts genetic relatedness in an alpine ungulate. Ecology 93:1317-1329

Short Bull RA, Cushman SA, Mace R, Chilton T, Kendall KC, Landguth EL, Schwartz MK, McKelvey K, Allendorf FW, Luikart G (2011) Why replication is important in landscape genetics: American black bear in the rocky mountains. Mol Ecol 20:1092-1107

Sommer S, McDevitt AD, Balkenhol N (2013) Landscape genetic approaches in conservation biology. Conserv Genet 14:249-251

Spear SF, Peterson CR, Matocq MD, Storfer A (2005) Landscape genetics of the blotched tiger salamander (Ambystoma tigrinum melanostictum). Mol Ecol 14:2553-2564

Spear SF, Balkenhol N, Fortin MJ, McRae BH, Scribner K (2010) Use of resistance surfaces for landscape genetic studies: considerations for parameterization and analysis. Mol Ecol 19:3576-3591

Steele CA, Baumsteiger J, Storfer A (2009) Influence of life-history variation on the genetic structure of two sympatric salamander taxa. Mol Ecol 18:1629-1639
Storfer A, Murphy MA, Evans JS, Goldberg CS, Robinson S, Spear SF, Dezzani R, Delmelle E, Vierling L, Waits LP (2007) Putting the "landscape" in landscape genetics. Heredity 98:128-142

Storfer A, Murphy MA, Spear SF, Holderegger R, Waits LP (2010) Landscape genetics: where are we now? Mol Ecol 19:3496-3514

Sutherland WJ, Adams WM, Aronson RB, Aveling R, Blackburn TM, Broad S, Ceballos G, Coté IM, Cowling RM, Da Fonseca GAB, Dinerstein E, Ferraro PJ, Fleishman E, Gascon C, Hunter M Jr, Hutton J, Kareiva P, Kuria A, Macdonald DW, Mackinnon K, Madgwick FJ, Mascia MB, McNeely J, Milner-Gulland EJ, Moon S, Morley CG, Nelson S, Osborn D, Pai M, Parsons ECM, Peck LS, Possingham H, Prior SV, Pullin AS, Rands MRW, Ranganathan J, Redford KH, Rodriguez JP, Seymour F, Sobel J, Sodhi NS, Stott A, Vance-Borland K, Watkinson AR (2009) One hundred questions of importance to the conservation of global biological diversity. Conserv Biol 23:557-567

Trumbo DR, Spear SF, Baumsteiger J, Storfer A (2013) Rangewide landscape genetics of an endemic pacific northwestern salamander. Mol Ecol 22:1250-1266

Turner MG (1989) Landscape ecology - the effect of pattern on process. Annu Rev Ecol Syst 20:171-197

Van Buskirk J (2012) Permeability of the landscape matrix between amphibian breeding sites. Ecol Evol 2:3160-3167

Van Strien MJ, Keller D, Holderegger R (2012) A new analytical approach to landscape genetic modelling: least-cost transect analysis and linear mixed models. Mol Ecol 21:4010-4023

Van Strien MJ, Keller D, Holderegger R, Ghazoul J, Kienast F, Bolliger J (2013) Landscape genetics as a tool for conservation planning: predicting the effects of landscape change on gene flow. Ecol Appl 24:327-339

Walzer C, Kowalczyk C, Alexander JM, Baur B, Bogliani G, Brun J-J, Füreder L, Guth M-O, Haller R, Holderegger R, Kohler Y, Kueffer C, Righetti A, Spaar R, Sutherland WJ, UllrichSchneider A, Vanpeene-Bruhier SN, Scheurer T (2013) The 50 most important questions relating to the maintenance and restoration of an ecological continuum in the European Alps. PLoS ONE 8:e53139

Wasserman T, Cushman S, Littell J, Shirk A, Landguth E (2013) Population connectivity and genetic diversity of American marten (Martes americana) in the United States northern rocky mountains in a climate change context. Conserv Genet 14:529-541

Weckworth BV, Musiani M, DeCesare NJ, McDevitt AD, Hebblewhite M, Mariani S (2013) Preferred habitat and effective population size drive landscape genetic patterns in an endangered species. Proc R Soc B Biol Sci 280:20131756

Winter M, Devictor V, Schweiger O (2013) Phylogenetic diversity and nature conservation: where are we? Trends Ecol Evol 28:199-204

Yannic G, Pellisiier L, Le Corre M, Dussault C, Beeernatchez L, Côté SD (2014) Temporally dynamic habitat suitability predicts genetic relatedness among caribou. Proc R Soc B Biol Sci 281:20140502 